\title{
«Ministros de tu Hijo Jesucristo» La dimensión cristológica del ministerio ordenado
}

\author{
«Ministers of your Son Jesus Christ» \\ The Christological Dimension of Ordained Ministry
}

ÁNGEL CORDOVILlA

\author{
Universidad Pontificia Comillas, Madrid \\ https://orcid.org/0000-0001-9217-2587 | acordovilla@comillas.edu \\ Fecha de recepción: 5/12/2021 \\ Fecha de aceptación: 22/12/21 \\ https://doi.org/10.52039/seminarios.v66vi229.889
}

RESUMEN: El ministerio ordenado es ante todo una configuración con Cristo. Esta dimensión ha de vivirse en la esencial condición de discípulos en el camino de seguimiento detrás del Señor; como apóstoles enviados en su misma misión; en las relaciones constitutivas que forman parte de la naturaleza del ministerio y, finalmente, en las tres funciones fundamentales que constituyen su ministerio: en el anuncio de la Palabra; en la santificación a través de la vida sacramental; y en el gobierno y la conducción de la comunidad eclesial. La configuración con Cristo no es solo el don que le es otorgado al presbítero con el sacramento del orden, sino la tarea más importante de su vocación realizada a través de las relaciones que son esenciales a su ser y el ejercicio del ministerio en el que se expresa de forma concreta su misión. Por lo tanto, la dimensión cristológica del ministerio no permite una comprensión estática y abstracta de este, sino que implica una comprensión relacional, apostólica y existencial.

PALABRAS CLAVES: representación de Cristo; discípulos; apóstoles, ministros.

ABSTRACT: The ordained ministry is first and foremost a configuration with Christ. This dimension has to be lived in the essential condition of disciples on the way of following behind the Lord; as apostles sent on their own mission; in the constitutive relationships that are part of the nature of the ministry and finally in the three fundamental functions that constitute its ministry: in the proclamation of the Word; in sanctification through sacramental life; and in the government and leadership of the ecclesial community. The configuration with Christ is not only the gift that is given to the priest with the sacrament of Holy Orders, but the most important task of his vocation carried out through the relationships that are essential to his being and the exercise of the ministry in which he is expresses its mission in a concrete way. Therefore, the Christological dimension of ministry does not allow a static and abstract understanding of it, but rather implies a relational, apostolic and existential understanding.

KEYWORDS: Representation of Christ; Disciples; Apostles, Ministers. 
«Para formar el pueblo sacerdotal, tú, Padre santo, dispones con la fuerza del Espíritu Santo en órdenes diversos a los ministros de tu Hijo Jesucristo» ${ }^{1}$. Así reza la plegaria de ordenación presbiteral al dirigirse a Dios Padre para ordenar a los nuevos presbíteros orientados al servicio de la vida de la Iglesia como pueblo sacerdotal. La perspectiva trinitaria es evidente, aunque por desgracia se olvida con frecuencia. Pero es la referencia a Jesucristo la que aparece en el centro para definir la naturaleza del ministerio: ministros de tu Hijo Jesucristo. La dimensión cristológica es el centro donde se integran y vertebran las diferentes perspectivas desde donde comprendemos el ministerio ordenado. En los últimos decenios ha sido necesario poner de relieve la dimensión pneumatológica o eclesiológica para no entender esta perspectiva cristológica de una forma aislada y absoluta. Pero esta necesidad de ponerla en relación con otras dimensiones no le resta nada de su centralidad. Si algo es el ministerio ordenado es una forma específica de configuración con Cristo. La referencia a él, de forma específica y singular, caracteriza la naturaleza del presbiterado. El manido argumento de que Cristo no fue sacerdote y que por lo tanto no puede justificarse un ministerio de este tipo en la Iglesia es una afirmación pueril y simplona. La persona de Jesús está más allá de las caracterizaciones que hoy hacemos de los estados de vida del cristiano. Estrictamente hablando, tal y como lo comprendemos hoy, él no es ni un laico, ni un sacerdote, ni un religioso. Cristo está más allá de todas las formas de vida cristiana, pues todas y cada una, en realidad, se fundamentan y tienen como modelo la persona de Cristo. Por lo que también, ninguna puede tener la pretensión de agotar lo que es y significa el misterio de su persona.

Es obvio que el ministerio ordenado no encuentra su fundamento en el sacerdocio veterotestamentario. La Carta a los Hebreos da pleno testimonio de ello, declarando superados tanto el sacrificio como el sacerdocio de la antigua alianza. Pero no es aquí donde se encuentra el fundamento del ministerio de la nueva alianza, por decirlo con la expresión de Pablo en la segunda Carta a los Corintios (2Cor 5,19-6,2) 2 $^{2}$ sino en la persona de Cristo. No es su actividad histórica entendida en términos laicales o sacerdotales lo que constituye el fundamento para entender el ministerio, sino su realidad personal como Señor Resucitado, cabeza de la Iglesia, desde donde tenemos que entender también después su realidad histórica y su ministerio del Reino, que obviamente también pertenecen al misterio de su persona.

1. Pontifical Romano. Ordenación del obispo, de los presbiteros y de los diáconos, Madrid 2011, n. ${ }^{\circ} 131$.

2. S. Guijarro, Servidores de Dios y esclavos vuestros. La primera reflexión cristiana sobre el ministerio, Salamanca 2011, esp. 59-104. 
Esta configuración con él es un don que se otorga a un bautizado a través del sacramento del orden. El primer nivel para entender esta realidad es el orden de la gracia. No obstante, junto a esta dimensión gratuita y carismática, se encuentra la dimensión ética y existencial, en la medida en que el don otorgado con la gracia del sacramento ha de convertirse en tarea de vida personal. El ministerio ordenado como representación de Cristo es a la vez el don y la tarea más importante y decisiva de la vida presbítero. Ésta ha de vivirse en la esencial condición de discípulos en el camino de seguimiento detrás del Señor; como apóstoles enviados en su misma misión; en las relaciones constitutivas que forman parte de la naturaleza del ministerio y finalmente en las tres funciones fundamentales que constituyen su ministerio: en el anuncio de la Palabra; en la santificación a través de la vida sacramental; y en el gobierno y la conducción de la comunidad eclesial ${ }^{3}$.

\section{El CARÁCter CENTRAL DE LA DiMENSIÓN CRISTOLÓGiCA}

La naturaleza, entendida como ser y misión, del ministerio apostólico presbiteral se define por su relación singular con Cristo. Aquí está la base fundamental de la comprensión del presbítero. El ministerio ordenado es una cuestión de ser, es decir, ontológica. Su origen concreto es el sacramento del orden, expresándose de este modo que se trata de un don de Dios a su Iglesia a través de la vocación y la existencia concreta de un cristiano bautizado que, al hacerlo partícipe del ser y la misión de Cristo, es constituido «presbítero». Este carisma esencial de la Iglesia se halla en el origen y tiene su punto de partida en la misión de Cristo y su llamada a los discípulos y apóstoles para «que estuvieran con él y enviarlos a predicar» (Mc $3,15)$. Esta estructura esencial que conecta con la conciencia de Cristo y su misión (origen cristológico radical) ha tenido después diversas configuraciones concretas a lo largo de la historia de la Iglesia, incluso en el propio Nuevo Testamento pueden descubrirse diferentes nombres procedentes de contextos culturales distintos.

Pero más allá de las formas concretas de configurar históricamente este don de Dios, en su esencia y estructura fundamental no estamos, por lo tanto, ante una creación de la comunidad cristiana, ni ante una pura institución humana generada desde las necesidades históricas y sociales. Estas han contribuido a darle una forma histórica determinada, que ha ido cambiando con

3. A. Cordovilla, "Como el Padre me envió, así os envío yo». Teología y espiritualidad del ministerio apostólico presbiteral, Salamanca ${ }^{2} 2021$. 
el tiempo y que podrá cambiar en el futuro ${ }^{4}$. Se trata de un don de Dios que viene de lo alto y que solo puede ser recibido a través de la gracia del sacramento. Con él la persona que lo recibe queda configurada especialmente con Cristo y ungida para una misión esencial y específica en la Iglesia. Como afirma J. Lecuyer, para la teología católica «ellos no son simples delegados del pueblo de Dios, sino que derivan de una institución que, a través de los apóstoles, remonta a Cristo mismo. La presencia de los ministros ordenados es, por tanto, en la comunidad cristiana, un signo permanente de la continuidad del don de Dios a su Iglesia: es Dios quien tiene la iniciativa» ${ }^{5}$.

\section{LA CONFIGURACIÓN CON CRISTO COMO DISCÍPULOS EN EL CAMINO DEL SEGUIMIENTO}

La primera concreción de la dimensión cristológica del ser y de la vida del presbítero se refiere a su condición de discípulo que camina detrás del Señor. Antes que apóstoles enviados, los presbíteros son discípulos llamados por Cristo para seguirle. Así fue con los primeros apóstoles: «Venid conmigo y os haré pescadores de hombres» $(\mathrm{Mc} 1,17)$ y así sigue siendo hoy en la vida de la Iglesia. No hay ministerio apostólico sin seguimiento; sin esta esencial condición discipular. El tiempo de preparación y formación para el sacerdocio no es otra cosa que la expresión de este camino del discípulo aprendiendo a configurarse con Cristo. Así lo afirma el decreto sobre la formación sacerdotal Optatam totius: «Puesto que han de configurarse por la sagrada ordenación a Cristo Sacerdote, acostúmbrese a unirse a él como amigos, en íntimo consorcio de vida» ${ }^{6}$. Pastores dabo vobis profundizó en esta comprensión de la formación para el sacerdote en el seminario como un «itinerario de vida», como un «seguimiento de Cristo como los apóstoles» ${ }^{7}$. Pero, si es así, esta comprensión de la formación no solo es válida para el tiempo antes de ser sacerdote, sino para su realización y desarrollo posterior. En efecto, la misma exhortación apostólica inscribe la formación permanente del presbítero en una «vocación en el sacerdocio... Hay un "sígueme" que acompaña toda la vida y misión del apóstol» ${ }^{8}$. El presbítero es siempre un

4. E. Castellucci, «Modelli di ministero sacerdotale nella storia», Revista Pistis \& Praxis: Teologia e Pastoral 7 (2015) 285-308.

5. J. Lecuyer, Le sacrament de l'ordenation. Recherche historique et théologique, Paris 1983, 271-272.

6. Concilio Vaticano II, Optatam totius 8.

7. Juan Pablo II, Pastores dabo vobis, 42.

8. Id., 70. 
discípulo en camino. No hay vida cristiana, ministerio y misión evangélica sin seguimiento de Cristo. Es lo primero de todo, pues según el relato de los evangelistas todo comienza por una llamada gratuita y soberana a seguir el Señor. Esto que es verdad en el inicio temporal de la vida cristiana y de la vocación sacerdotal, es a su vez un origen ontológico, es decir, el principio y el fundamento de todo su recorrido e itinerario. Todo miembro en la Iglesia es siempre y sólo discípulo del Señor, también quien ha recibido la llamada específica al ministerio apostólico y tenga la misión de representar a Cristo como cabeza de la Iglesia ${ }^{9}$.

Ser sacerdote no comienza por una decisión personal, sino por la llamada libérrima y gratuita de Dios que concita y convoca a la libertad humana. En una sociedad donde la libertad personal y autónoma se ha convertido en una realidad sagrada, contrasta mucho más que la vocación al ministerio comience por la decisión y la libertad de otra persona. Esta realidad cuesta percibirla, porque al inicio parece que se trata de una decisión personal que nace de la libertad individual, pero uno va aprendiendo que esto, sin ser falso, no es toda la verdad, ni siquiera la verdad primera ni la más radical. La historia de un sacerdote no comienza cuando él decide ser sacerdote e ingresar en un seminario, sino que siempre comienza en la llamada libérrima y gratuita de Dios. Él es quien decide, en su amor y misericordia, compartir con los seres humanos la misión de su Hijo, asociándolos a su tarea, a su misión y a su persona. Por mucho que un sacerdote avance en el camino de su vocación, siempre ha de ser consciente de que es un discípulo que sigue al Señor. El inicio de su ser y vocación no está en él, sino en ser llamado por Dios. Y por esta razón, pertenece a la esencia y la naturaleza de su vocación y de su vida mantenerse con fidelidad en el seguimiento de su Hijo.

La llamada de Jesús a sus discípulos a seguirle ante la irrupción del Reino de Dios en medio de los hombres nos ofrece un rasgo característico de la conciencia de Cristo y de su misión, que no es explicable desde las prácticas del judaísmo y del cristianismo primitivo ${ }^{10}$. Este ha de ser el punto de partida para una teología del ministerio y de la misión. Cuando más adelante la teología eclesial reflexione sobre el lugar natal del ministerio ordenado en la última cena de Jesús y en su entrega en el misterio pascual, este no podrá separarse de la llamada a seguirle como discípulos para ser enviados como

9. R. Williams, Ser discípulo. Rasgos esenciales de la vida cristiana, Salamanca 2019.

10. M. Hengel, Seguimiento y carisma. La radicalidad de la llamada de Jesús, Santander 1986, 126-129. 


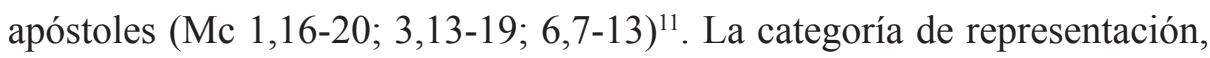
que está en la base de lo que luego denominaremos «actuar en representación de Cristo cabeza», tiene aquí su precedente y su raíz.

\section{LA CONFIGURACIÓN CON CRISTO COMO APÓSTOLES ENVIADOS}

La segunda perspectiva de esta dimensión cristológica del ministerio se refiere a la esencial condición de apóstoles de Jesucristo. El Concilio de Trento, queriendo responder al desafío de las tesis de Lutero y los reformadores sobre el carácter funcional y eclesial del ministerio, desarrolló una concepción del sacerdocio ministerial centrado esencialmente en su relación con el sacrificio de la misa y comprendido específicamente desde el poder sagrado de consagración y remisión de los pecados (potestas ordinis) ${ }^{12}$. De esta forma el ministerio presbiteral era defendido como ordo, es decir, como sacramento relacionado esencialmente con la eucaristía, según la doctrina de Santo Tomás de Aquino ${ }^{13}$. Trento defiende así que el sacerdocio presbiteral es una estructura esencial de la Iglesia y no puede ser reducido a una delegación de la comunidad o de la sociedad. El sacerdocio es un don de Dios a la Iglesia, determinado enteramente por el poder sacramental de la eucaristía y la penitencia en relación esencial al sacrificio de Cristo, no de una forma puntual o transitoria, sino con poder permanente (carácter) para actuar en persona Christi ${ }^{14}$.

El Concilio Vaticano II asume esta doctrina tridentina, pero al situarla en el cuadro más amplio de la misión de Cristo y de la Iglesia, supera una cierta comprensión reductora del ministerio vinculándolo casi exclusivamente al sacrificio de la misa y al poder de consagrar y perdonar los pecados. Sin negar esta relación, el Concilio pone el centro de referencia en el envío del Hijo por el Padre, donde a su vez es radicado el envío de la Iglesia y, en él, el de los apóstoles y sus sucesores, los obispos y, en colaboración con ellos, los presbíteros. Si en la teología de Trento y sobre todo de su recepción la palabra central de la teología del ministerio era potestas, aquí es missio. Es obvio que ambas están estrechamente relacionadas, pues el poder siempre es para una misión y la misión apostólica específica no puede realizarse sin el poder otorgado ${ }^{15}$ :

11. J. Marcus, El evangelio según Marcos (Mc 1-8), Salamanca 2010.

12. DH 1740.

13. Tomás de Aquino, Summa Theologica Supp. q.40, a.3.

14. D. Défois, Le pouvoir et la grâce. Le prêtre, du Concile de Trente à Vatican II, Paris 2013, 19-45.

15. J. Fontbona, Ministerio ordenado, ministerio de comunión, Centre de Pastoral Litúrgica, Barcelona 2009, 75, sintetiza en cinco puntos este desplazamiento de perspectiva: 1. El 
«[Párrafo 1]. El Señor Jesús, a quien el Padre santificó y envió al mundo (Jn 10,36), hizo partícipe a todo su cuerpo místico de la unción del Espíritu con que él está ungido [...].

[Párrafo 2]. El mismo Señor constituyó a algunos de ellos ministros que, ostentando la potestad sagrada en la sociedad de los fieles, tuvieran el poder sagrado del orden, para ofrecer el sacrificio y perdonar pecados, y desempeñaran en nombre de Cristo la función sacerdotal a favor de los hombres... Así, pues, enviados los apóstoles, como él había sido enviado por el Padre, Cristo hizo partícipes de su consagración y misión, por medio de los mismos apóstoles, a los sucesores de éstos, los obispos, cuya función ministerial se ha confiado a los presbíteros, en grado subordinado, con el fin de que, constituidos en el orden del presbiterado, fueran cooperadores del orden episcopal, para el cumplimiento de la misión apostólica que Cristo les confirió» ${ }^{16}$.

Este importante número del decreto Presbyterorum Ordinis forma parte del capitulo primero, donde se refiere al presbiterado en la misión de la Igle$\operatorname{sia}\left(\right.$ n. $\left.^{\circ} 2-3\right)$. El ministerio presbiteral es comprendido dentro de la entera misión de la Iglesia, que a su vez continúa y prolonga la misión de Cristo. Este número 2 del Decreto es el más importante porque recoge una breve síntesis doctrinal del ministerio presbiteral en la misión de la Iglesia.

Lo forman cinco párrafos. El primero evoca la doctrina del sacerdocio común. Todo el pueblo de Dios participa de la unción del Espíritu que define la misión y consagración de Cristo. Cada uno de los miembros de este cuerpo está llamado al culto a Dios (dimensión vertical) y a la misión en medio de los hombres (dimensión horizontal). El segundo párrafo, desde el horizonte de la misión de Cristo y de la Iglesia, vuelve a exponer el mismo contenido, pero ya aplicado al ministerio en su relación esencial con la misión apostólica. Desde este horizonte más amplio, y sin reducirlo a ello, recoge la doctrina tradicional del Concilio de Trento de la institución por Cristo,

punto de partida: de la eucaristía, a la misión de la Iglesia; 2. La institución: de la cena a la institución apostólica en su conjunto; 3. La especificidad del sacramento: del poder de consagración a la acción in persona Christi Capitis; 4 . El contenido del ministerio: de sacerdocio cultual al ministerio apostólico; 5 . La presencia del ministerio: del teocentrismo del culto al de toda la existencia y misión del presbítero.

16. Concilio Vaticano II, Decreto sobre el ministerio y la vida de los presbiteros $(P O), 2$. A mi juicio, $P O$ sigue siendo el punto de partida y el marco adecuado para entender el ministerio presbiteral en la Iglesia. Sin pretender elaborar un tratado teológico del ministerio ordenado, el Decreto ofreció y sigue ofreciendo las coordenadas esenciales para la comprensión renovada y profunda del sacerdocio. Esto no significa que no pueda ser desarrollado y completado en cuestiones que entonces no fueron tratadas. No olvidemos que $P O$, como último documento aprobado por el Concilio, hay que entenderlo a la luz de toda la doctrina conciliar, especialmente de las cuatro grandes constituciones y sobre todo de Lumen Gentium. D. Vitali, «Le novità del Concilio Vaticano II sul ministero ordinato», Seminarios 66 (2021) 97-116. 
su carácter público, del poder sagrado para la celebración de la eucaristía y la capacidad para actuar en representación de Cristo. El tercer párrafo se refiere a la naturaleza sacramental de este ministerio y el poder sagrado y apostólico: marcados por el Espíritu, configurados con Cristo para obrar en nombre de Cristo Cabeza (in persona Christi capitis). El cuarto párrafo se refiere a la misión del presbítero concretando los aspectos anteriores en el clásico triple ministerio de Cristo (tria munera Christi), que son la misión de toda la Iglesia y que cada bautizado vive de manera diferente: el anuncio del evangelio; la misión de congregar al pueblo de Dios; ofrecer el culto y sacrificio eucarístico agradable al Padre. No hay una oposición entre culto y evangelización en la misión de la Iglesia y del presbítero (Rom 15,16), entre la orientación teocéntrica y antropocéntrica del ministerio sacerdotal. El párrafo 5 se refiere, finalmente, a este objeto último de la vida sacerdotal, que podemos expresar con la formulación clásica: la gloria de Dios (teocentrismo) y la vida del hombre (misión antropocéntrica) ${ }^{17}$.

Por tanto, según la doctrina conciliar, el punto de partida para comprender el ministerio ordenado es la consagración y misión del Hijo enviado por el Padre, que no excluye, sino que integra en un horizonte más amplio la relación del sacerdocio con el sacrificio redentor de Cristo actualizado sacramentalmente en la eucaristía ${ }^{18}$. A esta misión está unido todo su cuerpo, que es la Iglesia, ungida y enviada por el mismo Espíritu de Jesucristo. Con una misión y consagración especial son enviados los apóstoles y sus sucesores, los obispos. Y desde este ministerio apostólico se comprende el ministerio ordenado de los presbíteros. Su función es «obrar en nombre de Cristo Cabeza» en tres órdenes o ministerios: el de la Palabra y anuncio del Evangelio; el de los sacramentos y la celebración de la Eucaristía; el de la guía y conducción del Pueblo de Dios en su camino hacia el Reino. Por esta razón, el nombre más apropiado para el sacerdote es el de «apóstol de Jesucristo». Como pone de relieve la teología actual, el ministerio presbiteral está en continuidad histórica y esencial con el ministerio apostólico, cuya misión y naturaleza es ser signo de Cristo como cabeza de la Iglesia, haciéndolo presente a través de sus obras y palabras ${ }^{19}$.

17. J. Frisque, «Decreto Presbyterorum ordinis. Historia y comentario», en F. Marty et alii, Los sacerdotes, Madrid 1969, 127-209; aquí 145-151; O. Fuchs, «Presbyterorum ordinis. Kommentierung», en, Herders theologischer Kommentar, vol. IV, Freiburg-Basel-Wien 2009, 411-542; aquí 418-432; P. Hünermann, «Zur Gewichtung von Presbyterorum ordinis», en id., 543-569.

18. Y. Congar, «El sacerdocio del Nuevo Testamento. Misión y culto», en F. Marty et alii, Los sacerdotes, 269-300; esp. 282-286.

19. G. Greshake, Ser sacerdote hoy, Sígueme, Salamanca 2003, 121: «El ministerio eclesiástico, que a pesar de la permanente primacía del ministerio apostólico se halla en conti- 
El término apóstol significa literalmente enviado ${ }^{20}$. En el Nuevo Testamento es un término que aparece especialmente en las cartas paulinas y en Hechos de los Apóstoles con una diferencia significativa en su aplicación. Mientras que para Pablo es un término desde el que se describe a aquel que tiene la tarea de proclamar el evangelio con una autoridad dada por Dios (Rom 1,1; Gal 1,15; 2,8; 2Cor 5,19; 1Tes 2,4-9), para la teología lucana, apóstol es un término reservado a los Doce, dirigentes de la comunidad de Jerusalén (Hch 4,35-37; 5,2) cuya tarea fundamental es la transmisión y la conservación de la doctrina (Hch 2,42). Podríamos decir que hay un sentido restrictivo que remite a los Doce con la importancia que tiene la institución de este grupo en el origen y fundamento de la Iglesia y un sentido amplio que puede ser aplicado a quien tiene el encargo de realizar una misión determinada en nombre de quien lo envía.

El significado del término apóstol en el NT y en la teología posterior recoge el «uso jurídico popular del término hebreo saliah que, según las fuentes judías, es el representante directo de quien le envía y puede actuar en representación suya de manera autoritativa y jurídicamente vinculante ${ }^{21}$. En la imagen del apóstol y del enviado, no solo está la idea de la misión encomendada, sino también la misión de representación y la capacitación jurídica para hablar u obrar en nombre de quien envía. Aquí nos encontramos en la base bíblica de un concepto teológico tan denso e importante para el ministerio ordenado como «representación $»^{22}$. Como expresa Marcelino Legido: «Enviar significa enviar con poder. El enviado es el rostro del quien le envía. 'El enviado de un hombre es este mismo' (Berach 5,5). La misión es una mediación para la inmediatez de quien envía. El enviado, por tanto, es un representante. Más que representar al que le envía, el que envía se hace presente en el enviado. Inmediatamente, presencialmente ${ }^{23}$.

El término apóstol nos sirve tanto para entender la relación entre el Padre y el Hijo, como la relación de Cristo con los apóstoles enviados por él. Así

nuidad con él en el aspecto histórico y de su contenido, muestra fundamentalmente la misma estructura y la misma forma interna de este: hacer presente en la Iglesia y para la Iglesia -en constante referencia al normativo testimonio apostólico- la acción de Jesucristo mismo y se halla, por tanto, como "representante de Cristo" frente a los demás creyentes y las capacidades de los mismos obradas (también) por el Espíritu)».

20. J.-A. Bühner, «apostolos», en H. Balz - J. Schneider (eds.), DENT I, 427-438.

21. Id., 431.

22. E. Persson, Repraesentatio Christi. Der Amtbegriff in der neuen römisch-katholischen Theologie, Göttingen 1966.

23. M. Legido, «Conformar la vida con el misterio de la cruz del Señor», en Espiritualidad del presbitero diocesano secular. Simposio, Madrid 1986, 101-191; aquí 113. 
aparece con nitidez en el evangelio de Juan en el encuentro de Jesús resucitado con sus discípulos comunicándoles su aliento, su Espíritu, para hacerles partícipes de su misma misión: «Como el Padre me ha enviado, así os envío yo» (Jn 20,21). Desde este punto de vista, podemos decir que el apóstol por antonomasia es Cristo (Heb 3,1), ya que él es quien ha sido enviado con poder por el Padre para hacerlo presente en medio de los hombres. Dios se hace presente a través de su Hijo, enviado al mundo por el amor apasionado por sus criaturas (Jn 3,16-17). Él es su rostro, su imagen, su impronta, por lo que puede decir que «quien le ve a él, ve a quien le ha enviado» (Jn 12,44-45). De la misma forma, o análogamente, Jesús, al enviar a sus discípulos con una serie de advertencias, les dice: «Quien a vosotros acoge, a mí me acoge y quien me acoge a mí, acoge a Aquel que me ha enviado» (Mt 10,40). Los apóstoles son ahora su imagen, su rostro, su palabra y su presencia. Esta estructura de representación que aparece en la Escritura desde la teología del envío ha terminado cuajando en la expresión técnica fundamental para la comprensión del ministerio ordenado de actuar en nombre de Jesucristo (agere in persona Christi $)^{24}$, y que sigue siendo el foco desde donde se plantean algunas de las discusiones en torno al ministerio ordenado en la actualidad ${ }^{25}$.

\section{In persona Christi}

El presbítero actúa en nombre de Cristo, pero no es Cristo. Esto provoca una tensión fundamental entre la actuación en nombre y representación de Cristo como cabeza de la Iglesia y la frágil existencia personal del ministro que lo representa. El que envía se hace presente en quien es enviado, pero se hace presente en la fragilidad de la existencia del sacerdote. Reconocer este hecho y esta diferencia esencial es vital para la vida del presbítero. Como afirmó Benedicto XVI en la homilía de la clausura del año sacerdotal el 11 de junio de 2010: «El sacerdocio no es un simple 'oficio', sino un sacramento: Dios se vale de un hombre con sus limitaciones para estar, a través de él, presente entre los hombres y actuar en su favor. Esta audacia de Dios, que se abandona en las manos de seres humanos; que, aun conociendo nuestras

24. B. D. Marliangeas, Clés pour une théologie du ministére: In persona Christi, in persona Ecclesiae, Paris 1978; G. Greshake, Ser sacerdote hoy, 121-147; A. Favale, «La relación del presbítero con Cristo», en Espiritualidad del presbitero diocesano secular. Simposio, Madrid 1986, 203-231; aquí 217-221; S. del Cura Elena, «La sacramentalidad del sacerdote y su espiritualidad», en Espiritualidad sacerdotal. Congreso, Madrid 1989, 73-119; aquí 103-111.

25. M. Eckholt - J. Rahner (Hrsg.) Christusrepräsentanz. Zur aktuellen Debatte um die Zulassung von Frauen zum priesterlichen Amt, Freiburg 2021. 
debilidades, considera a los hombres capaces de actuar y presentarse en su lugar, esta audacia de Dios es realmente la mayor grandeza que se oculta en la palabra 'sacerdocio'».

Un momento decisivo para la dilucidación del sentido de esta actuación en nombre de Cristo respecto a la vida concreta del presbítero fue la controversia donatista, que tuvo lugar entre los siglos III y V en el norte de África. Es cierto que es una situación límite y no puede ser esgrimida como forma normal de la dispensación de los misterios de $\operatorname{Dios}^{26}$. Los sacramentos dispensados por el sacerdote que ha traicionado la fe católica, ¿son válidos? Los sacerdotes que llevan una vida pecadora, ¿tienen capacidad para santificar a través de sus palabras? La respuesta entonces fue afirmativa, porque ellos no representan a Cristo sustituyéndolo, sino que es Cristo quien por la fuerza del Espíritu se hace presente en su acción sacramental. Es Cristo quien anuncia el Evangelio, quien bautiza, quien preside la eucaristía. Todos, el sacerdote el primero, ha de ser consciente de este desfase y distancia entre su ser y la misión encomendada. La vida del sacerdote, entendida como un proceso ascético, debe ir acercando cada vez más estas dos dimensiones, pero siendo consciente siempre y con humildad de que esta distancia, tensión y paradoja son infranqueables. El sacerdote no es [otro] Cristo, sino que es Cristo quien se hace presente a través de los gestos, palabras y acciones del sacerdote. Él no es Cristo, sino apóstol de Cristo y esclavo del Señor (Rom $1,1)$, que lo puede hacer presente personalmente, es decir, en su persona, gracias a la unción y acción del Espíritu ${ }^{27}$. La persona y la acción de Cristo son absolutamente únicas y singulares, irrepetibles e insuperables. Por esta razón su representación ministerial a través del sacramento del orden no puede ser

26. En este sentido tiene razón J. M. Tillard, «The ordained "Ministry" and the "Priesthood" of Christ» One in Christ 14 (1978) 239, al afirmar: «Desde la crisis donatista estamos demasiados marcados por la distinción entre lo que es necesario en casos específicos y lo que no es necesario. Más bien habrá que poner el énfasis en lo que es normal. Algunas teologías del ministerio son teologías de lo estrictamente necesario, y no teologías de "servicio al sacerdocio de Cristo"». Tomado de I. Oñatibia, «La espiritualidad del presbítero desde la sacramentalidad de su ministerio», en $\mathrm{P}$. Tena et alii, El nuevo ritual de la ordenación sacerdotal (Cuadernos Phase 50), Barcelona 1994, 57-79; aquí 68.

27. Esta integración de la dimensión pneumatológica en la cristológica en la teología del ministerio es esencial. Así lo ha puesto de relieve entre otros S. del Cura Elena, «En la fuerza del Espíritu. Dinamismo pneumatológico y espiritualidad sacerdotal», Theologica 45 (2010) 59-92; aquí 76: «La fuerza santificadora del Espíritu Santo aparece como la fuerza consecratoria decisiva, que permite al sacerdote retomar in persona Christi las palabras del Señor, cuyo memorial se celebra, y que hace del mismo algo fructuoso y vivificante para todos los que en él participan. La precedencia del Espíritu Santo evita así el riesgo de confundir al ministro de la liturgia con el autor de la gracia y de identificar al sacerdote con el verdadero dispensador de los dones divinos». 
entendida en términos de «suplencia, sucesión, complemento o prolongación», sino más bien en términos «icónico-sacramentales» como símbolo, imagen, figura, representación de Cristo ${ }^{28}$.

Desgraciadamente, debido a crímenes execrables e injustificables, en el momento actual de la historia de la Iglesia, esta verdad fundamental hemos tenido que aprenderla de una forma excesivamente brusca ${ }^{29}$. No podemos, ni debemos, idealizar la vida de los curas, ni exigirles la santidad de Jesucristo. La santidad es de la Iglesia y el resto de los miembros somos pecadores que intentamos no ser obstáculo a la mediación salvífica que Cristo obra por medio de cada uno de nosotros, mientras trabajamos arduamente en nuestra santificación. Ser representación de Cristo en la actuación salvífica no puede llevar a una consideración angélica de los sacerdotes. La expresión clásica, muy utilizada antiguamente y todavía hoy en algunos contextos eclesiales, de que el sacerdote es alter Christus, siendo verdadera y teniendo una intuición válida, puede conducir a un grave error. El sacerdote no sustituye la presencia de Cristo, sino que como ya hemos dicho hace presente su persona sacramentalmente. Por otro lado, la mediación sacramental nunca es pura trasparencia; siempre se da en la ambigüedad y fragilidad de la existencia humana. No a pesar de ella, sino en ella, a través de ella. Ésta es la audacia de Dios. Y así lo entendió Pablo de Tarso cuando en la segunda carta a los Corintios afirma desde su experiencia personal que la fuerza y gracia de Dios se realiza en la debilidad del apóstol (2Cor 4,7; 12,9-10). Asumir con humildad esta pobreza y vivirla como un acicate para la vida de santificación personal es algo constitutivo de la naturaleza del apostolado, pues hace que no pueda apropiarse nunca de nada: ni del evangelio, ni de la comunidad eclesial a la que es enviado, ni de los frutos apostólicos que puedan darse a través de su acción pastoral, es decir, hace que el ministro sea más consciente de que es apóstol de Jesucristo y esclavo de su Señor. Es ahí, y no en el éxito, donde puede decir realmente aquella otra expresión paulina de que «ya no soy yo, sino que es Cristo quien vive en mi» $(\mathrm{Gal} 2,20)$.

\section{Como instrumentos vivos}

Por esta razón, este ser y acción del ministerio presbiteral de representar a Cristo que nace de la gracia de Dios y depende de la acción del Espíritu, repercute en la persona y la vida del ministro como un camino de espiritua-

28. I. Oñatibia, «La espiritualidad del presbítero, 69.

29. R. Dodaro, «El sacerdote como pecador en el pensamiento de san Agustín», en, G. Uríbarri (ed.), El ser sacerdotal, Madrid 2010, 109-118. 
lidad. Así lo afirma Ignacio Oñatibia: «Por ser ‘instrumentos vivos’ (PO 12), conservan su inteligencia y su voluntad libre y, por tanto, su capacidad para dejarse afectar, marcar, modelar y moldear por la acción de Dios que interviene a través de ellos para la salvación de los hombres» ${ }^{30}$. El agua de la gracia que actúa e interviene a través del cauce de la persona del ministro ha de ir trasformando no solo a los destinatarios de esa acción, sino al intermediario e incluso más al mediador. El cristianismo es una religión de mediaciones personales para la inmediatez con Dios. Todo lo que al final no pasa por la libertad y la conciencia de sus mediadores termina degradándose. Esta configuración y seguimiento es íntima y personal. Dios no se comunica a nosotros sólo desde la objetividad externa, sino desde la intimidad de nuestra conciencia y el sagrario de nuestro ser personal. El Espíritu que ungió a Cristo, es el mismo Espíritu que nosotros recibimos para poder participar en su vida más íntima (fraternidad) y en su misión universal (comunicación): en su misma intimidad y obediencia, que es lo que configura su misma oración al Padre (Gal 4,6; Rom 8,16); en su misma conciencia (1Cor 2,16); en sus mismos sentimientos de amor hasta el extremo por los otros hermanos como forma fundamental de vida en Iglesia (Flp 2,5); en su misma misión de extender la reconciliación y la paz a todos (Jn 20,19-23); en su misma victoria $($ Rom 8,11$)$ que es compartida y extendida hasta la misma creación (Rom 8,22-30).

El reconocimiento de la primacía de Dios y de su gracia en la vida y acción ministerial del presbítero, cuando es auténtico y verdadero, conduce a una real vivencia de la gratuidad y del servicio. Por un lado, para vivir desde el agradecimiento y la acción de gracias por el don de Dios recibido inmerecidamente; desde «la alegría de saberse elegido por Dios» ${ }^{31}$ y la confianza de que la obra que Dios comenzó en ti y que él se trae entre manos, él mismo la llevará a término ${ }^{32}$. Pero, por otro lado, para vivir desde la humildad y el temor de Dios, de quien sabe que la obra no es suya, que todo depende de la acción de Dios, que el poder y la autoridad que ostenta, provienen de la fuerza y sabiduría de Dios (1Cor 1-2). Y, finalmente, para vivir desde la docilidad y la conformación a la voluntad del Padre, que como para Cristo, ha de ser nuestro alimento y nuestro sustento (Jn 4,48).

30. I. Oñatibia, «La espiritualidad del presbítero, 63.

31. Id., 64.

32. Pontifical Romano, 125: «Dios que comenzó en ti la obra buena, él mismo la lleve a término». 


\section{LA CONFIGURACIÓN CON CRISTO EN LAS RELACIONES CONSTITUTIVAS}

El ser de Cristo es relación. Por esta razón, si el sacerdote se configura con el misterio de su persona, también ha de incluir esta dimensión esencialmente relacional. Las relaciones que el presbítero vive en el ejercicio de su ministerio no son accidentales, sino que están inscritas en la naturaleza de su ser sacerdotal. Estas relaciones son fundamentalmente dos: con la Iglesia y con el mundo, aun cuando deberíamos decir en la Iglesia y en el mundo.

El ministerio ordenado se da en la Iglesia y en una forma constitutivamente eclesial. Junto a la intransferible llamada personal, realizada desde el propio nombre, Jesús llamó a los discípulos como grupo (Doce) y fueron enviados «de dos en dos». La naturaleza del ministerio ordenado puede ser resumido y concentrado en la expresión representatio Christi Capitis, pero esta representación no puede darse si no es a su vez participando en la entera misión de la Iglesia como representatio Ecclesiae. No es el presbítero de forma aislada quien está llamado y capacitado para ser y hacer esta representatio, sino en cuanto miembro de un presbiterio unido a quien es principio y signo de la unidad eclesial: el obispo. La incardinación real, no solo jurídica, de un presbítero en la Iglesia local es la expresión concreta de esta dimensión esencialmente eclesial de su ministerio. Aunque esta referencia a la Iglesia no sea prioritaria respecto a la referencia cristológica, sin embargo, sigue siendo necesaria en la definición de la identidad del presbítero ${ }^{33}$. Si la relación a Cristo es prioritaria en cuanto es el fuente y fundamento del sacramento del orden, su radicación en la Iglesia es esencial ${ }^{34}$. La relación con Cristo no puede vivirse sino en la relación jerárquica con el obispo (relación vertical), y en la relación fraterna con quienes participan conjuntamente del sacramento del orden y la relación fraterna radical con quienes comparte el don y la vocación bautismal y con quienes comparte la propia humanidad (relación horizontal).

\section{Relación eclesial: con el obispo, el presbiterio y los fieles laicos}

Los sacerdotes han de asumir de verdad en su forma de vida y en el trabajo pastoral que la «representación de Cristo cabeza y pastor de su Iglesia» no es del sacerdote aislado que lo hace todo y sabe hacer de todo, sino la del obispo con su presbiterio en la diversidad de acciones y formas de vida. $P O 8$ tiene

33. Juan Pablo II, Pastores dabo vobis 12.

34. S. del Cura Elena, «La sacramentalidad del sacerdote y su espiritualidad», en Espiritualidad sacerdotal. Congreso, Madrid 1987, 73-119; esp. 85-98. 
una expresión muy clara al respecto al referirse a las diversas actividades de los presbíteros como una única misión sacerdotal: «De hecho, aunque se consagren a diversas tareas, realizan, sin embargo, un único ministerio sacerdotal a favor de los hombres». Y, antes, en el número 7, para expresar la necesaria relación con el obispo, afirma: «Ningún presbítero, por tanto, puede realizar bien su misión de manera aislada e individualista, sino únicamente juntando las fuerzas con otros presbíteros bajo la dirección de los que presiden la Iglesia».

Junto a esta dimensión comunitaria del ser sacerdotal respecto al obispo y otros sacerdotes, hay que tener en cuenta que el sacerdote es un «hermano entre hermanos» con otros miembros de la Iglesia. Que el presbítero sea apóstol de Cristo que actúa en representación suya como cabeza de la Iglesia, no puede inducir a pensar que el sacerdote está fuera de la Iglesia. La alteridad que significa este actuar en nombre de Cristo ha de ser correspondida con la conciencia de ser y vivir en la comunión íntima de la Iglesia como uno más. No para disolver su ministerio en el sacerdocio común o entenderlo desde una delegación de la comunidad cristiana hacia él para el ejercicio y desempeño de una función, sino para enraizar de hecho su ministerio en la comunión eclesial. Esta doble perspectiva articula la relación entre el presbítero y la comunidad eclesial en la que vive y es enviado. Es un hermano entre iguales por el sacramento del bautismo y es un padre al frente de la comunidad cristiana en virtud del sacramento del orden. No puede el presbítero renunciar a su presidencia de la comunidad y a la autoridad apostólica que ha recibido del Señor para el ministerio y el servicio de la comunidad, así como no puede vivir esta autoridad de forma autoritaria, y separado de la comunidad cristiana. El número 9 de $P O$ manifiesta esta tensión inherente al ministerio y la vida del presbítero por esa doble implantación sacramental en la Iglesia, que existencialmente ha de ser una: por el sacramento del orden son «padres y maestros» y por el bautismo «hermano entre hermanos».

\section{Relación mundana: secularidad}

Finalmente, la dimensión cristológica del ministerio a través de las relaciones constitutivas del ser y la misión del presbítero nos conduce a su esencial carácter secular. Así lo comprende de nuevo el Concilio Vaticano II al colocar en un díptico el número 2 sobre la naturaleza del presbiterado y el número 3 sobre la condición de los presbíteros en el mundo. Ambos están dentro del capítulo I titulado «el presbiterado en la misión de la Iglesia». La razón última de la secularidad del presbítero es cristológica. El texto 
conciliar se inspira en la cristología joánica para quien la acción salvífica de Cristo en el mundo puede ser resumida con la categoría de envío. Cristo es, sin más, el enviado (Jn 9,7). El concepto santificación que aparece unido al de envío, que después se ha sido entendido como consagración, es interpretado claramente en la línea de la misión y de la unción, no tanto de la separación del «hombre de Dios», aislado del pueblo que actúa de mediador entre Dios y los hombres en un lugar intermedio entre ambos. La secularidad, por tanto, viene exigida por nuestro origen en Dios, que nos envía, y por el destino donde somos enviados: al mundo. No serían fieles al designio salvífico de Dios si su vida permanece separada de la vida de los hombres a los que son enviados.

Esta radicación esencial del ministerio en el mundo (secularidad) viene justificada a su vez por la cristología de la Carta a los Hebreos. Cristo es sacerdote no separándose de los hombres, sino haciéndose solidario de ellos, a quienes puede llamar sus hermanos (Heb 2, 10-18; 5,1-10). Por eso, los presbíteros, a imagen de Cristo, son tomados de entre los hombres (ex hominibus) y constituidos a favor de ellos (pro hominibus). La solidaridad radical del sacerdote con los hombres es para la proexistencia, es decir, la vida y el ser volcados literalmente hacia y por los demás. Si hablamos de secularidad del presbítero, no bastaría con mostrar que el sacerdote es el hombre con los demás, sino que ese 'con' es la condición de posibilidad para ser el hombre 'para' los demás. Dicho de otra forma. En la persona de Cristo, con la encarnación, Dios nos ha mostrado que él es el Emmanuel, el Dios con nosotros (Mt 1,23; 28,19); en su entrega a la muerte se nos ha revelado más radicalmente como el Dios por nosotros (Rom 8,32). Entre el misterio de la encarnación y el misterio de la pascua se encuentra la clave de comprensión de la secularidad de Cristo y, por ende, de la secularidad del sacerdote. En ese pro (íxદ́p) se concentra el misterio de la entrega de Cristo, que no vino a ser servido, sino a servir y entregar su vida en rescate por muchos (Mc 10,45).

\section{LA CONFIGURACIÓN CON CRISTO EN LA MISIÓN}

Como ya hemos dicho, el sacramento del orden es un don dado por Dios por el que un bautizado queda configurado a Cristo, como cabeza y pastor de la Iglesia. Es una realidad que afecta a su ser para realizar una determinada misión. Ambas perspectivas no se pueden separar. Y nuevamente nos ayuda a entender esta relación la persona de Jesucristo. En él, persona y misión se identifican. De esta forma, resulta artificial la discusión de si en la com- 
prensión del ministerio ordenado ha de primar una perspectiva ontológica o funcional. El ser es para la misión, más aún, el ser es misión; así como la misión no puede ser realizada sino desde el ser; la misión es ser realmente lo que somos por el sacramento para otros y en beneficio de otros.

\section{Ministerio profético en el anuncio del Evangelio}

El presbítero se configura a Cristo en la medida que como él pone su vida enteramente al servicio del Evangelio de Dios. Ser apóstol de Cristo obliga a anunciar su evangelio. No es simplemente un oficio, sino una necesidad teológica y existencial $(1 \mathrm{Cor} 9,16)$. Nuevamente $P O$ es muy clara al respecto: «El pueblo de Dios se reúne, sobre todo, por la palabra de Dios vivo, la cual es muy lícito buscarla en la boca del sacerdote. Nadie puede salvarse si antes no ha tenido fe. Por eso, los presbíteros, como colaboradores de los obispos, tienen como primer deber el anunciar a todos el Evangelio de Dios» ${ }^{35}$. La vida y la misión del sacerdote no solo se expresa desde su relación con la eucaristía, sino en primer lugar por la relación esencial con la palabra de Dios que ha de acoger, trasmitir y realizar en medio del mundo. Sin el ejercicio del ministerio de la Palabra no sería posible convocar al Pueblo de Dios ni cumplir el mandato de Cristo de llevar el evangelio a todas las gentes. La Iglesia se edifica y crece desde la escucha fiel y obediente de la Palabra. Ella es la discípula del Señor que se pone a sus pies para realizar lo único necesario: aprender de su maestro acogiendo en su corazón las palabras de vida eterna que salen de su boca. La piedra de cimiento de la comunidad cristiana es Cristo, por eso la edificación de la Iglesia ha de realizarse sobre la palabra de Dios.

No es el carisma personal del presbítero ni de ningún miembro o grupo eclesial el centro y el fundamento de la vida comunitaria, por importante que pueda ser para el ejercicio concreto del ministerio y para la vida de la Iglesia. Este ha de ponerse al servicio del anuncio del evangelio y del ministerio de la palabra para que la edificación de la Iglesia se realice sobre la roca de cimiento que la funda, la sostiene y la hace crecer. Para que esta edificación sobre la palabra pueda ser real, el presbítero ha de ejercer su ministerio como profeta y como maestro.

El ministerio profético trata de percibir la presencia de Dios en los acontecimientos de la historia. De alguna manera, se trata de una actualización

35. PO 4. F. Wulf, «Kommentar zu Artikel 1-6», en Lexikon für Theologie und Kirche. Das Zweite Vatikanische Konzil III, Freiburg 1968, 156-164; O. Fuchs, «Kommentierung. Der Dienst der Presbyter», Freiburg 2009, 436-443. 
de la palabra: desde ella iluminamos nuestra vida cotidiana con el fin de aprender a descubrir la voluntad de Dios en la vida cotidiana; y, por otro lado, esta vida cotidiana es juzgada desde ella. El maestro es aquel que desgrana toda la riqueza que se encuentra escondida en la palabra de Dios y que ha sido el desencadenante de una larga y rica tradición eclesial. El presbítero deberá alternar su misión profética y su misión docente dentro del único ministerio de la palabra, pues ambas dimensiones son necesarias en la vida de crecimiento de la comunidad cristiana ${ }^{36}$.

\section{Ministerio sacerdotal en la celebración de los sacramentos}

Si hay un lugar donde se ha visibilizado la esencial relación del presbítero con la persona de Cristo es a través de la celebración de los sacramentos, especialmente de la penitencia y de la eucaristía. Aquí el yo de Cristo se hace presente a través de nuestro yo personal: "yo te bautizo..."; "tomad y comed esto es $m i$ cuerpo..."; "yo te absuelvo...". Aun sabiendo que se trata de una identidad de representación sacramental, tal y como hemos explicado más arriba, estas palabras no dejan de expresar la profundísima unidad que se produce entre Cristo y la persona del ministro.

Pero, la tarea fundamental del presbítero en este ministerio no es tan solo la celebración de estos sacramentos, que obviamente hay que realizar de la forma más adecuada y significativa posible como ponen de relieve las preguntas que se hacen al presbítero en la ordenación sacerdotal y son renovadas en la renovación de las promesas en la misa crismal. El verdadero desafío para la vida del presbítero y su tarea de configuración personal con Cristo es que estos se conviertan en su forma de vida, es decir, que configuren su existencia sacerdotal. Así lo ponía de relieve Juan Pablo II en la última carta que les escribió a los sacerdotes con motivo del Jueves Santo en el año dedicado a la eucaristía desde el policlínico Gemeli de Roma: «Puesto que toda la Iglesia vive de la eucaristía, la existencia sacerdotal ha de tener, por un título especial, 'forma eucarística'. Por tanto, las palabras de la institución de la eucaristía no deben ser para nosotros únicamente una fórmula consagratoria, sino también una «fórmula de vida» ${ }^{37}$. De esta forma el Papa ponía en evidencia la estrecha relación que existe entre la eucaristía y la existencia del presbítero. Siguiendo fundamentalmente las palabras de la consagración, lo especificó como una «existencia profundamente agradecida», una «existencia entregada, una existencia

36. G. Lafont, La sabiduría y la profecía. Modelos teológicos, Salamanca 2008.

37. Juan Pablo II, Carta a los sacerdotes con ocasión del Jueves Santo de 2005, 1. 
salvada para salvar», una «existencia que recuerda», una «existencia consagrada», una «existencia orientada a Cristo», una «existencia eucarística aprendida de María».

Teniendo en cuenta esta perspectiva, la estructura de la celebración de la eucaristía es todo un programa para la existencia del presbítero: los ritos iniciales o la llamada a una existencia para la comunión desde la conciencia de que el fundamento de la comunión es la Trinidad (saludo inicial), vivida desde la confesión humilde de las culpas (acto penitencial) y la audacia de la confesión del señorío de Cristo (Kyrie y Gloria). La liturgia de la palabra o la necesidad una existencia para la palabra que nos sitúa como oyentes, servidores y hacedores de la palabra. La liturgia eucarística o la exigencia de una existencia para los demás desde la gratitud y el agradecimiento (acción de gracias) en una vida que se reparte y comparte (fracción del pan) y finalmente se da y entrega por los hombres (sacrificio). Los ritos de despedida o la necesidad de una existencia misionera. La existencia para la comunión desde el misterio trinitario se convierte aquí en una existencia para la misión desde la bendición del Padre, del Hijo y del Espíritu.

\section{Ministerio pastoral en la guía y presidencia de la comunidad}

La tercera dimensión de la configuración con Cristo a través de la misión nos lleva al ministerio pastoral. El sacerdote es ante todo un pastor. Pero, ¿en qué consiste este ministerio pastoral o servicio de pastor? PO 6 nos ofrece las líneas fundamentales. En primer lugar, el texto nos indica el trasfondo fundamental desde donde hay que comprender el ejercicio de este

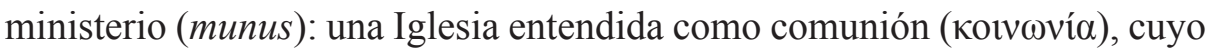

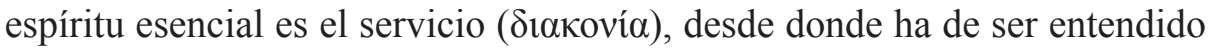
el poder de representar a Cristo como cabeza de la Iglesia (potestas). Ministerio y autoridad constituyen una unidad inseparable, para que la autoridad no degenere en un autoritarismo despótico ni el ministerio en una función vacua, puramente administrativa o delegacional ${ }^{38}$. La potestas sacerdotal o la auctoritas apostólica es la versión sacramental de la غ̇̌́ovoía de Cristo de la que nos hablan los evangelios, desde la que él realiza su ministerio profético anunciando el evangelio y curando toda enfermedad y dolencia. En una autoridad para la liberación de los oprimidos (Mc 1,27). En esa misma autoridad son enviados los apóstoles para realizar los mismos gestos y acciones liberadoras de Jesús (Mc 3,15). La potestad sagrada concedida al presbítero

38. O. Fuchs, «Presbyterorum Ordinis. Kommentierung», Herders Theologischer Kommentar zum Zweiten Vatikanischen Konzil, vol. 4, Freiburg 2009, 449-451. 
con la ordenación sacramental como una gracia divina es para la edificación, para reunir y conducir a la comunidad eclesial para que sea más Iglesia (comunión) y camine de una forma más decidida hacia el Reino (misión). Esa potestas que de una forma muy significativa ha estado vinculado al poder sobre los dones en la eucaristía y a perdonar los pecados en el sacramento de la penitencia hay que entenderla en este cuadro más amplio como gracia y autoridad espiritual (potestas spiritualis) para la edificación del pueblo de Dios. Ni se trata, por lo tanto, de un privilegio personal o de un poder individual otorgado para el crecimiento de la dignidad o estatus del sacerdote, sino como un don al servicio del crecimiento del cuerpo de Cristo hacia su plena madurez.

\section{Ministerio del Espiritu}

El ministerio presbiteral como ejercicio de la representación de Cristo cabeza es así también un ministerio del Espíritu ${ }^{39}$, razón por la cual el ejercicio del ministerio es fuente de espiritualidad y lugar en el que hay que buscar la plenitud de la vocación propia en la santificación y en el camino de perfección. Así lo afirma el Concilio Vaticano II en un paso que resulta decisivo en la comprensión de la espiritualidad del presbítero: «Por las mismas acciones sagradas de cada día, así como por todo el ministerio entero, que ejercen unidos al obispo y a los presbíteros, ellos mismos de ordenan a la perfección de vida $»^{40}$. «Los presbíteros conseguirán propiamente la santidad ejerciendo sincera e infatigablemente en el Espíritu de Cristo su triple función $»^{41}$. El Concilio logró un cambio radical en una comprensión clásica que hablaba de la santidad necesaria para ejercer el ministerio, a la afirmación de la santidad del presbítero que parte y nace del ejercicio del ministerio; de la santidad para el ministerio a la santidad en el ministerio ${ }^{42}$.

El Concilio Vaticano II reorientó de una forma decisiva lo que en la jerga de la espiritualidad clásica se conocía como vida ascética. Esta no es recomendada solo, o al menos exclusivamente, desde una perspectiva individual (la santidad personal del presbítero), sino que lo que está en juego además es la renovación interna de la Iglesia, el anuncio del evange-

39. PO 12.

40. PO 12.

41. PO 13.

42. S. Gamarra, «La espiritualidad presbiteral y el ejercicio ministerial según el Vaticano II», en Espiritualidad del presbitero diocesano secular, 461-482; aquí 482. 
lio y el diálogo con el mundo actual. Por así decirlo, tiene una visión más eclesial, apostólica y social de las implicaciones que tiene la vida personal del presbítero en el ejercicio de su ministerio al tratar de adecuar su vida y su espíritu a la vida y al Espíritu de Cristo, es decir, de hacer que su ser representación de Cristo sea realizado desde el ministerio del Espíritu. Esta es la fuente y el cometido fundamental de su santificación. Y, por esta razón, no tiene que buscar su santificación personal en medios o en ejercicios distintos a lo que es el contenido esencial de su ministerio como el anuncio de la Palabra, la celebración de los sacramentos y la guía del pueblo de Dios. Como afirma Ottmar Fuchs en su comentario a $P O$ : «a través de las tres funciones acontece la santificación del pueblo de Dios y la misma santificación del presbítero ${ }^{43}$. La representación de Cristo ha de ser vivida en el ministerio del Espíritu, dejando que el Espíritu de Cristo unja nuestro cuerpo, ilumine nuestra inteligencia, trasforme nuestro corazón y santifique nuestra vida.

\section{Caridad pastoral}

Ahora bien, no todo lo que un presbítero hace es sin más fuente de santificación. Su acción ha de estar unida a Cristo como profeta, sacerdote y pastor. Es Cristo quien otorga al presbítero la unidad de vida en medio de tantas actividades y ministerios, y el que hace posible que estos no sólo no obstaculicen su vida espiritual y su camino de santidad, sino que más bien sean precisamente su vehículo específico. La caridad pastoral no es algo separado de la persona de Cristo, sino que es Cristo en el ejercicio de su misión en absoluta obediencia al Padre $($ Jn 4,34$)$ y en su amor único y personal volcado por cada uno de sus hermanos (Jn 10,15) ${ }^{44}$. Juan Pablo II le dio una gran importancia a esta realidad en la vida del presbítero, desarrollando la doctrina del Concilio:

El principio interior, la virtud que anima y guía la vida espiritual del presbítero en cuanto configurado con Cristo cabeza y pastor es la caridad pastoral, participación en la misma caridad pastoral de Jesucristo: don gratuito del Espíritu Santo y, al mismo tiempo, deber y llamada a la respuesta libre y responsable del presbítero. El contenido esencial de la caridad pastoral es la donación de $\sin ^{45}$.

43. O. Fuchs, «Presbyterorum Ordinis. Kommentierung», 485.

44. PO 14.

45. Juan Pablo II, Pastores dabo vobis, 23. 
La caridad pastoral nace de la consagración en la ordenación sacerdotal. Es una potestas spiritualis para regir al pueblo de Dios, acompañando, guiando, conduciendo, haciendo crecer al pueblo de Dios hacia la plena madurez en la libertad y el amor. Se trata de una configuración a Cristo como buen pastor en su apasionada solicitud por los perdidos; en su reunión de los dispersos y en la entrega de la vida por todos (Jn 10). El contenido de esta caridad pastoral es la entrega de sí mismo. No es tanto lo que hacemos, sino la donación personal en eso que hacemos, «la donación de nosotros mismos». Por eso esta caridad pastoral tiene su forma plena de expresión en la eucaristía, lugar de realización y fuente continua para la vida del presbítero. Así, la caridad pastoral se convierte en principio interior y dinámico de la vida del presbítero con la capacidad de unificar las múltiples acciones en las que desarrolla su vida y ministerio pastoral. La unidad, por lo tanto, no está en la acción misma, sino en la realización de esa acción desde la unión con Cristo y la caridad del buen pastor. Se trata, por lo tanto, de una relación personal y personalizadora, realizada a través del ejercicio del ministerio, tal y como hemos visto antes, y de todo lo que hace el presbítero, especialmente la vida interior para asegurar la fidelidad a Cristo y la vida fraterna para asegurar la fidelidad a la Iglesia ${ }^{46}$. Es importante subrayar esta doble especificación del ejercicio de la caridad pastoral desde la vida interior y la vida fraterna, que lejos de excluirse, se implican. Lo que está en juego es la fidelidad, la vinculación personal y subjetiva del presbítero a Cristo y a su cuerpo que es la Iglesia. No solo la vinculación sacramental objetiva que es dada con la ordenación y la administración de los sacramentos ex opere operato, sino la participación subjetiva y personal del presbítero en el ser personal de Cristo: sus sentimientos, su mente, su vida. Esto solo puede hacerse si hay efectivamente un cultivo de la dimensión espiritual e interior en la vida del presbítero.

\section{Configuración con Cristo: don y tarea}

La configuración con Cristo es un don que se da a los presbíteros con el sacramento del orden, pero de la misma manera que hay que prepararse para este don a través del camino del discipulado, que nunca termina, tal configuración constituye, al mismo tiempo, la tarea esencial de su vida a través del ejercicio del ministerio y de la totalidad de la vida del presbítero. Así se lo recuerda el obispo en la ordenación sacerdotal al recibir la patena y el cáliz

46. PDV 23-25. Entre la innumerable bibliografía: V. Siret (ed.), La charité pastoral. Colloque à Ars (27-29 janvier), Paris 2014. 
llevados por los fieles para la celebración de la eucaristía: «Recibe la ofrenda del pueblo santo para presentarla a Dios. Considera lo que realizas, imita lo que conmemoras y conforma tu vida con el misterio de la cruz del Señor» ${ }^{47}$. La configuración con Cristo o el paulino «ser en Cristo» no es solo el don que le es otorgado al presbítero con el sacramento del orden, sino la tarea más importante de su vocación realizada a través de las relaciones que son esenciales a su ser y el ejercicio del ministerio en el que se expresa de forma concreta su misión. Por lo tanto, la dimensión cristológica del ministerio no permite una comprensión estática y abstracta de este, sino que implica una comprensión relacional, apostólica y existencial.

\section{BIBLIOGRAFÍA}

Bühner, J.-A., «apostolos», en H. Balz - J. Schneider (eds.), Diccionario Exegético del Nuevo Testamento I, Salamanca 1996, 427-438.

Castellucci, E., «Modelli di ministero sacerdotale nella storia», Revista Pistis \& Praxis: Teologia e Pastoral 7 (2015) 285-308.

Concilio Vaticano II, Optatam totius. Decreto sobre la formación sacerdotal, Acta Apostolicae Sedis 58 (1966) 713-727.

-Presbyterorum ordinis. Sobre el ministerio y vida de los presbiteros. Acta Apostolicae Sedis 58 (1966) 991-1024.

Congar, Y., «El sacerdocio del Nuevo Testamento. Misión y culto», en F. Marty et alii, Los sacerdotes, Madrid 1969, 269-300.

Cordovilla, A., «Como el Padre me envió, así os envío yo». Teología y espiritualidad del ministerio apostólico presbiteral, Salamanca ${ }^{2} 2021$.

Défois, D., Le pouvoir et la grâce. Le prêtre, du Concile de Trente à Vatican II, Paris 2013.

del Cura Elena, S., «La sacramentalidad del sacerdote y su espiritualidad», en Espiritualidad sacerdotal. Congreso, Madrid 1989, 73-119.

- «La sacramentalidad del sacerdote y su espiritualidad», en Espiritualidad sacerdotal. Congreso, Madrid 1987, 73-119.

-«En la fuerza del Espíritu. Dinamismo pneumatológico y espiritualidad sacerdotal», Theologica 45 (2010) 59-92.

Dodaro, R. «El sacerdote como pecador en el pensamiento de san Agustín», en, G. Uríbarri (ed.), El ser sacerdotal, Madrid 2010, 109-118.

47. Pontifical Romano, n. ${ }^{\circ} 135$. 
Eckholt M., - Rahner J. (Hrsg.), Christusrepräsentanz. Zur aktuellen Debatte um die Zulassung von Frauen zum priesterlichen Amt, Freiburg 2021.

Favale, A., «La relación del presbítero con Cristo», en Espiritualidad del presbitero diocesano secular. Simposio, Madrid 1986, 203-231.

Fontbona, J., Ministerio ordenado, ministerio de comunión, Centre de Pastoral Litúrgica, Barcelona 2009.

Frisque, J., «Decreto Presbyterorum ordinis. Historia y comentario», en F. Marty et alii, Los sacerdotes, Madrid 1969, 127-209.

Fuchs, O., «Presbyterorum ordinis. Kommentierung», en, Herders theologischer Kommentar, vol. IV, Freiburg-Basel-Wien 2009, 411-542.

Gamarra, S., «La espiritualidad presbiteral y el ejercicio ministerial según el Vaticano II», en Espiritualidad del presbitero diocesano secular, Madrid 1986, 461-482.

Greshake, G., Ser sacerdote hoy, Salamanca 2003.

Guijarro, S., Servidores de Dios y esclavos vuestros. La primera reflexión cristiana sobre el ministerio, Salamanca 2011.

Hengel, M. Seguimiento y carisma. La radicalidad de la llamada de Jesús, Santander 1986.

Hünermann, P., «Zur Gewichtung von Presbyterorum ordinis», en Herders theologischer Kommentar, vol. IV, Freiburg-Basel-Wien 2009, 543-569.

Juan Pablo II, Exhortación apostólica postsinodal Pastores dabo vobis, Acta Apostolicae Sedis 84 (1992) 657-804.

- Carta a los sacerdotes con ocasión del Jueves Santo, 13 de marzo de 2005.

Lafont, G., La sabiduría y la profecía. Modelos teológicos, Salamanca 2008.

Marliangeas, B. D., Clés pour une théologie du ministére: In persona Christi, in persona Ecclesiae, Paris 1978.

Legido, M., «Conformar la vida con el misterio de la cruz del Señor», en Espiritualidad del presbitero diocesano secular. Simposio, Madrid 1986, 101-191.

Lecuyer, J., Le sacrament de l'ordenation. Recherche historique et théologique, Paris 1983.

Marcus, J. El evangelio según Marcos (Mc 1-8), Salamanca 2010.

Persson, E., Repraesentatio Christi. Der Amtbegriff in der neuen römisch-katholischen Theologie, Göttingen 1966.

Pontifical Romano. Ordenación del obispo, de los presbiteros y de los diáconos, Madrid 2011.

Siret, V., (ed.), La charité pastoral. Colloque à Ars (27-29 janvier), Paris 2014. 
Tena P. et alii, El nuevo ritual de la ordenación sacerdotal (Cuadernos Phase 50), Barcelona 1994, 57-79.

Tomás de Aquino, Suma de Teología. Suplementos.

Vitali, D., «Le novità del Concilio Vaticano II sul ministero ordinato», Seminarios 66 (2021) 97-116.

Williams, R., Ser discípulo. Rasgos esenciales de la vida cristiana, Salamanca 2019.

Wulf, F., «Kommentar zu Artikel 1-6», en Lexikon für Theologie und Kirche. Das Zweite Vatikanische Konzil III, Freiburg 1968, 156-164. 